\title{
La incidencia de los conceptos de división, separación y equilibrio de poderes públicos en la jurisprudencia constitucional colombiana
}

\author{
The incidence of the concepts of division, separation and balance of public powers in \\ Colombian constitutional jurisprudence
}

DOI: https://doi.org/10.21803/penamer.14.27.456

\section{Cesar Alejandro Cano Mendoza \\ https://orcid.org/0000-0001-9694-9998}

¿Cómo citar este artículo?

Cano, C. (2021). La incidencia de los conceptos de división, separación y equilibrio de poderes públicos en la jurisprudencia constitucional colombiana. Pensamiento Americano, 14(27), 57-

79. DOI: https://doi.org/10.21803/penamer.14.27.456

\section{Resumen}

Introducción: El Estado históricamente ha trazado horizontes encaminados hacia lo que se consideró el deber ser del Estado. Objetivo: analizar la incidencia de los conceptos de división, separación y equilibrio de poderes públicos en la Jurisprudencia Constitucional Colombiana. Método y metodología: abordaje metodológico hermenéutico jurídico y analítico. Resultados y Conclusiones: se requiere de cada uno de los poderes del Estado lo ejerzan organismos de manera autónoma. El texto investigativo es desarrollado en el marco de las siguientes líneas de investigación de la Universidad Libre de Colombia: (i) Derecho, Estado, cultura y sociedad, (ii) Desarrollo social y Económico; y (iii) Desarrollo sostenible, tecnología e Innovación.

Palabras clave: división, separación, equilibrio de poderes

\begin{abstract}
Historically, the State has drawn horizons towards what was considered the duty of the State, for which the objective of analyzing the incidence of the concepts of division, separation and balance of public powers in the Colombian Constitutional Jurisprudence arises, based on a methodological hermeneutical legal and analytical approach; which allowed to identify and conclude that each of the powers of the State is required to be exercised by agencies autonomously. The investigative text is developed within the framework of the following research lines of the Universidad Libre de Colombia: (i) Law, State, culture and society, (ii) Social and Economic Development; and (iii) Sustainable development, technology and Innovation.
\end{abstract}

Keywords: division, separation, balance of powers

*Artículo científico resultado de investigación, presentado para optar el título de Magíster en derecho administrativo de la Universidad Libre de Bogotá, describe resultados de procesos en desarrollo del posgrado cursado. Artículo presentado con fines de publicación en revista académica indexada. 
Resumo

aa

Palavras-chave: aa

Abogado. Especialista en Derecho Electoral, Maestrante en derecho administrativo de la Universidad Libre Sede Principal. Correo electrónico institucional: cesara-canom@unilibre.edu.co 


\section{Introducción}

En el año 1789, con la autoproclamación del tercer estado como Asamblea Nacional Constituyente, es donde los registros históricos acreditan el nacimiento de la Revolución francesa por causa de la enorme crisis económica por la cual atravesaban en Francia y de la cual los más golpeados eran, principalmente, los burgueses y los campesinos. Fue en ellos sobre los cuales recayeron todas las cargas tributarias y éstas eran administradas sin mayores criterios por la monarquía para satisfacer hasta sus más mínimos deseos (Lozano, 2004).

Esta situación habría comenzado a terminar con la paciencia y obediencia de esta clase social y a partir de entonces comenzarían a reorganizar el Estado, las decisiones y los manejos que allí se daban, orientados por la sensación de injusticia que los llevó a tomar posturas duras como que estas determinaciones las ejecutarían con la monarquía, sin la monarquía o contra la monarquía.

Posterior a la rotunda decisión del pueblo de constituirse para cambiar los aspectos que los afectaban, hubieron múltiples causas adicionales a la antes mencionada que fueron también causas principales de la revolución francesa, entre tantas causas que dieron luz a este suceso se encuentra que el régimen monárquico absolutista gracias a su excesiva rigidez afianzaba en las masas un gran malestar generalizado que obedecían a sus intentos fallidos de atajar la evidente crisis económica y política que para entonces ya había penetrado las bases de la economía y peor aún las conciencias del pueblo (Mirkine-Guetzevitch, 2008, p.114).

Por otra parte, fue fundamental y determinante la situación de desesperación que padecieron los habitantes de las zonas rurales y zonas urbanas populares, esto por causa del incremento acelerado, inconsecuente e injusto de los impuestos, derechos señoriales y reales, al mismo tiempo aumentaban los precios de los productos a los cuales ellos tenían que hacerse en el mercado porque no los producían y los necesitaban para cubrir sus necesidades básicas insatisfechas. (Lozano, 2004).
Lo anterior para entender claramente cuáles fueron los antecedentes que provocaron que más tarde tuviera lugar la Revolución francesa, por otra parte, las ideas de tres grandes precursores de la época tales como Juan Jacobo Rousseau, Voltaire y Montesquieu que hablaban de los derechos de ciudadano, la igualdad y la terminación definitiva del régimen aplicable en el momento (Vergara, 2012). Cada uno de ellos de forma proporcional tuvo su contribución ideológica que logró penetrar las conciencias de las personas en Francia hasta tomar la decisión definitiva de tomarse el poder por las vías de hecho y plantear la reorganización del Estado y de sus formas ejercerlo.

Revisando la historia el contexto general de la división de poderes surge como resultado de las teorías mecanicistas del siglo XVII cuya base fue la génesis de la ciencia moderna describiendo el mundo como una máquina cuyas funciones se reducían a las sencillas reglas universales que se pueden expresar en lenguaje matemático. Durante los siglos XVII y XVIII los pensadores utilizaban las metáforas del reloj y la balanza para explicar el argumento básico de la teoría de la división de poderes.

\section{Según el autor Mirkine-Guetzevitch (2008):}

la metáfora del reloj se convierte en una ilustración de una concepción general del orden que es aplicable a las más diversas áreas de experiencia [...]. La autoridad central se comunica con los miembros subordinados del sistema a través de rígidas relaciones unidireccionales y que no permiten signos de retorno. (p.115).

La metáfora de la balanza es la imagen de un sistema dotado de capacidad de autorregulación que asegura de forma automática la preservación del equilibrio entre sus elementos. Esta teoría llevará a una defensa de la libertad frente a un Estado intervencionista, con lo que el reloj, símbolo del despotismo ilustrado, se opone a la balanza, símbolo de libertad. Este equilibrio hay que trasladarlo al esquema institucional, de manera que aquél puede lograrse, pero depende del esquema mecánico que lo regule. (p.116). 
El sistema interno de gobierno y los poderes implícitamente mantienen la imagen del reloj y de la balanza "pues el sistema político logra un auto equilibrio únicamente a partir de un diseño que lo induzca a ello. Y este es el proyecto que llevará a cabo Montesquieu" (Mirkine-Guetzevitch, 2008, p.115). El Espíritu de las Leyes, en esta obra publicada en el siglo XVIII por Montesquieu, matemático humanista que experimenta en el campo de las ciencias sociales con la aplicación de métodos matemáticos newtonianos tratando de acercar la generalidad con el humano.

No depender de los hombres, sino de la ley, de un equilibrio de poderes que imponga cierta estabilidad y sirva de barrera a la ambición y vicios de los hombres”. En las apreciaciones del autor la naturaleza del hombre no sería posible si no existieran las instituciones que generan resistencia al constante cambio de las pasiones humanas estableciendo que la constitución delinea instituciones que tienen efectos en la realidad. De acuerdo con esto las estructuras institucionales deben ser sencillas en busca de mecanismos más simples en los que los elementos se equilibran y alcanzan la moderación, característica esencial del buen gobierno. Según Montesquieu, este es el sistema de pesos y contrapesos. Este es el momento en que el autor llega a la formulación de la teoría de la división de poderes en el Libro XI Capítulo VI de la obra, que textualmente dice:

He aquí, pues, la constitución fundamental del gobierno al que nos referimos: el cuerpo legislativo está compuesto de dos partes, cada una de las cuales tendrá sujeta a la otra por su mutua facultad de impedir, y ambas estarán frenadas por el poder ejecutivo que lo estará a su vez por el legislativo. Los tres poderes permanecerían así en reposo o inacción, pero, como por el movimiento necesario de las cosas están obligados a moverse, se verán forzados a hacerlo de común acuerdo. (Mirkine-Guetzevitch, 2008, p.116).

La idea de la división de poderes lleva implícita como consecuencia inmediata la imperturbabilidad de las leyes. El sistema diseñado por Montesquieu se fundamenta en la racionalidad funcional con validez universal, que se diferencia claramente del gobierno mixto. Es así como en la segunda mitad del siglo XVIII la división de poderes se convierte en paradigma constitucional del Estado de derecho, portando algunas dificultades en lo referente a la perdurabilidad por la pérdida de vigencia de los presupuestos en los cuales se basaba.

Posterior a la rotunda decisión del "pueblo" de constituirse para cambiar los aspectos que los afectaban, hubo múltiples causas adicionales a las antes mencionada que fueron también causas principales de la Revolución francesa, entre tantas causas que dieron luz a este suceso se encuentra que el régimen monárquico absolutista gracias a su excesiva rigidez afianzaba en las masas un gran malestar generalizado que obedecían a sus intentos fallidos de atajar la evidente crisis económica y política que para entonces ya había penetrado las bases de la economía y peor aún las conciencias del pueblo.

De acuerdo con Cerra (2017), la autonomía de la voluntad tiene su origen más cierto y concreto al ubicarlo en Emmanuel Kant, quien fue el primero en desarrollar científicamente el postulado de la autonomía de voluntad del ser humano consistiendo, pues, en la libertad o poder que tenía el ser humano de dictarse sus propias normas morales (p.8).

Un abordaje a la naturaleza del sujeto, sus dualidades y complejidades. Morín (2003) demuestra el valor de la reivindicación de la condición de ser y sujeto, que se expresa desde la manifestación alternativa (desobediente) "frente a la necesidad de comunicación, reivindicación y bienestar” (Díaz, 2012, p. 268).

Por lo anterior, de la Revolución francesa, sus causas y consecuencias se puede concluir que estos sucesos establecieron el concepto y definición aplicada de democracia, derechos de la igualdad y de los ciudadanos, para suprimir la figura de un ser supremo y desligar los poderes que este ejercía sobre el pueblo, y finalmente de esta forma ser el mismo pueblo quien postulara y escogiera a quienes iban a 
ser quienes tomaran las decisiones colectivas y de competencia plural. Así las cosas ya los monarcas no serían quienes establecieran las leyes por las cuales se regiría el pueblo, tampoco serian quienes administraran a su arbitrio e interpretación esas leyes y mucho menos serian quienes impondrían, recaudarían y administrarían feudos, impuestos y demás aportes de carácter tributario, es decir, posterior a la revolución el pueblo seguiría existiendo, también el estado pero se necesitaban nuevas formas de organizar el Estado y es donde, se dividen las funciones o los poderes públicos en tres principalmente, ejecutivo, legislativo y judicial.

El poder ejecutivo con funciones naturalmente administrativas, de ejecución de planes, proyectos y políticas públicas para el conglomerado de ciudadanos, como primer responsable de las relaciones diplomáticas con otros Estados, también con fines estratégicos de tomar decisiones que orienten el rumbo del Estado, entre otras, de las funciones principales del poder ejecutivo de un Estado moderno (Vergara, 2012).

El poder legislativo con funciones creacionistas de las leyes y del ordenamiento normativo, jurídico y social propiamente dicho, que regirá a la población y que deberá ser acatado de forma estricta. A partir de la producción legislativa también se parametrizan y limitan tanto al Estado como a sus ciudadanos con relación a los comportamientos y conductas que serán permitidos, como también los que serán reprochados socialmente y sancionados con posterioridad. En otras palabras, este poder señalar la hoja de ruta por la que se podrá transitar en dicho Estado, lo que se podrá hacer y como ejecutarlo y así mismo lo que será prohibido en el correspondiente territorio (Vergara, 2012).

Se tiene como tercer poder del Estado el judicial, este tendrá como fin principal velar por que el principio universal de la justicia prime y sea el faro que guie la solución de conflictos que puedan suscitarse entre particulares y particulares y el Estado. Este poder va íntimamente ligado a las interpretaciones y principios generales del derecho y está sujeto a la aplicación práctica y casuística de lo que el poder legislativo se encarga de crear, las leyes.

La metodología de estudio utilizada para abordar el contexto jurisprudencial del equilibrio de poderes fue un análisis descriptivo y analítico de las decisiones de la Corte Constitucional en diferentes momentos de la historia, desde sus primeras sentencias relacionadas con nuestro tema de interés, hasta las más recientes y actualizadas jurisprudencias afines. El primer periodo para estudiar será el comprendido entre los años 1991 hasta el 2000 y el segundo periodo que se estudiará, será desde el año 2001 hasta la más reciente jurisprudencia afín con el principio de equilibrio de poderes, emitida por la Corte Constitucional. Finalmente, se ofrecerán unas conclusiones y apuntes críticos que atiendan al tratamiento que han recibido las referidas figuras jurídicas a lo largo de la existencia de la Honorable Corte Constitucional. Para el análisis jurisprudencial sobre el principio de separación de poderes, división de poderes y equilibrio de poderes, se realizará un análisis descriptivo de las decisiones de la Corte Constitucional en su edad temprana (período 1991 hasta el año 2000), para después identificar el desarrollo que han tenido estas instituciones desde el año 2001 hasta la más reciente jurisprudencia emitida por este alto tribunal.

\section{Contexto Jurisprudencial}

Habiendo identificado genéricamente las funciones principales de lo que se ha definido como los tres poderes del poder público, ejecutivo, legislativo y judicial, se hace pertinente abordar cómo se enmarcan estos conceptos en un Estado en particular, en este caso, el Estado colombiano y la Constitución de 1991 y sus reformas, que es la Constitución que actualmente los colombianos reconocen como su Carta Magna vigente.

El concepto de separación de poderes podría describirse acertadamente como lo hizo la Corte Constitucional que en Sentencia C 630-14 describe el concepto como: "el principio de separación de poderes se encuentra plasmado en el artículo 113 de la Carta 
Política”, siendo uno de los propósitos de la Corte en razón de lo cual ha propuesto modelos para la separación de poderes: "El primero de ellos es un modelo estático que se enfoca primordialmente en la necesidad de limitar el ejercicio del poder en el diseño de los órganos, entidades e instituciones públicas" (p.70). De acuerdo con Sierra (2010) en la Sentencia C-141 de 2010 concibe la separación de poderes como un sistema que garantiza que el ejercicio del poder pueda limitarse en la medida en que los diversos órganos del poder público tengan funciones diferentes, y que éstas se encuentren perfectamente bien definidas en la Constitución y la ley (p.25).

Para el segundo modelo de acuerdo con Sierra (2010):

es menester que los diversos órganos del poder público ejerzan controles recíprocos, y para ello es necesario que haya una cierta medida de concurrencia o complementariedad en el ejercicio de sus funciones respectivas. En segunda medida, si bien los derechos típicamente liberales requieren limitar los poderes del Estado para garantizar el ámbito de libertad de las personas, los derechos de prestación requieren un aumento de la capacidad del Estado para garantizar su efectividad. (p. 26)

\section{$\mathrm{Al}$ respecto la Corte y Según Sierra (2010):}

Desde esta perspectiva, el equilibrio de los poderes es una consecuencia natural de la autonomía de órganos con funciones constitucionalmente bien delimitadas. En consecuencia, el control que ejerce un órgano sobre otro en relación con el cumplimiento de sus propias funciones es básicamente un control político, que se da de manera tanto espontánea como ocasional, y sólo frente a casos extremos. Precisamente, la rigidez de la separación de poderes condenaba este modelo al fracaso, por la dificultad de su implementación práctica, pues la falta de vasos comunicantes entre los distintos órganos estatales conducía a enfrentamientos difíciles de solucionar en la práctica, cuyo resultado natural y obvio tendía a ser la re- afirmación del poder en los órganos, autoridades o funcionarios que se estiman política y popularmente más fuertes (p. 28).

La antítesis que jurídicamente pretende contraponerse a lo anterior, el segundo modelo, conocido como sistema de "frenos y contrapesos" o "balances y contrapesos" se preocupa por profundizar el ejercicio del poder. Admite que para salvaguardar la plena libertad de los ciudadanos es necesario el control del ejercicio del poder que es aplicado por el Estado, pero que esta función requiere y demanda herramientas y un sistema que le permita a los órganos del poder público controlarse equilibradamente entre sí.

Reconoce además que para asegurar la existencia de una medida amplia y suficiente de identidad entre los ciudadanos es vital diseñar estrategias de cooperación entre las instituciones del Estado que admitan el fortalecimiento del poder del Estado, y encauzarlo para el logro de sus objetivos. En este orden de ideas, este modelo admite que un nivel mínimo de complementariedad, cooperación y concurrencia entre los poderes públicos para que el Estado pueda garantizar además de las libertades básicas de los ciudadanos también los derechos prestacionales de que gozan los mismos.

Por lo anterior, la Corte en la sentencia C-971 de 2004 ha dicho:

Según Cepeda (2004) De acuerdo con el segundo modelo, la delimitación rígida de las funciones constitucionales es insuficiente para garantizar el cumplimiento de los cometidos estatales e impedir el ejercicio arbitrario del poder. Desde dicha perspectiva, este modelo le otorga un papel preponderante al control y a las fiscalizaciones interorgánicas recíprocas, como reguladores constantes del balance entre los poderes públicos- Sistema de checks and balances (p.38).

Para Cepeda (2004) El modelo constitucional de frenos y contrapesos no presupone el equilibrio entre los órganos que detentan las funciones clásicas del poder público como consecuencia espontánea de una 
adecuada delimitación funcional. Por el contrario, el balance de poderes es un resultado que se realiza y reafirma continuamente, y que no puede relegarse a un control político contingente, eventual o accidental, cuyo resultado natural y obvio tiende a ser la reafirmación del poder en los órganos, autoridades o funcionarios que se estiman política y popularmente más fuertes. (p.38).

De la misma forma, en la citada Sentencia C-141/10 se hace referencia de manera puntual a la forma de como los controles recíprocos y la cooperación son la limitante al concepto aplicado de separación de poderes en nuestro sistema constitucional, afirmando que:

El modelo adoptado respeta el criterio conforme al cual, en virtud del principio de separación, las tareas indispensables para la consecución de los fines del Estado se atribuyen a órganos autónomos e independientes. No obstante, la separación resulta morigerada por las exigencias constitucionales de colaboración armónica y por controles recíprocos. En virtud de las primeras, se prevé, por un lado, una labor de coordinación entre los órganos a cuyo cargo está el ejercicio de las distintas funciones, y, por otro, se atenúa el principio de separación, de tal manera que unos órganos participan en el ámbito competencial de otros, bien sea como un complemento, que, según el caso, puede ser necesario o contingente -por ejemplo la iniciativa gubernamental en materia legislativa- o como una excepción a la regla general de distribución funcional -como el ejercicio de determinadas funciones judiciales por el Congreso o la atribución de funciones jurisdiccionales por medio de la ley en materias precisas a determinadas autoridades administrativas-.

La Corte Constitucional en su función primordial de salvaguardar la integridad de la Constitución Política (Art. 241), ha adelantado juicios de constitucionalidad sobre las normas con fuerza de ley, bien a través de demandas de constitucionalidad promovidas por los ciudadanos o porque ha debido hacer exá- menes previos de constitucionalidad sobre normas enviadas por el Congreso de la República o el mismo presidente. En desarrollo de esta responsabilidad se ha manifestado en diferentes oportunidades sobre las instituciones que hoy nos atañen (separación de poderes, división de poderes y equilibrio de poderes), en aras de sustentar las declaratorias de inexequibilidad sobre normas que amenazan con desdibujar el diseño institucional de pesos y contrapesos (check and balances) instituido por el constituyente de 1991.

\subsection{Periodo de 1991 - 2000}

Sentencia C - 004 de 1992, en la que fuera la primera sentencia de la recién creada Corte Constitucional, la C-004 de 1992 cuyo Magistrado Ponente fue el Dr. Eduardo Cifuentes Muñoz, se menciona de manera tangencial el concepto de separación de poderes para advertir en ese momento que:

De acuerdo con Cifuentes (1992) La visión de una rígida separación de los poderes debe ser superada en la concepción que concilia el ejercicio de funciones separadas - que no pertenecen a un órgano sino al estado - con la colaboración armónica para la realización de sus fines, que no son otros que los del servicio a la comunidad (CP arts. 2 y 113). La técnica de organización del poder que la constitución contempla para épocas de anormalidad consulta fundamentalmente la necesidad de estructurar una respuesta rápida y eficaz frente a la misma con la preservación de un mecanismo particular de separación de funciones. La función legislativa es asumida por el Gobierno y sin agotar el trámite legislativo ordinario, por la vía de los decretos legislativos, se busca articular un eficiente mecanismo de respuesta. La función de control, según la técnica clásica de frenos y contrapesos, le corresponde al Congreso que, de todas maneras, conserva la plenitud de sus atribuciones. (p.44)

Cabe destacar en este punto que la decisión sobre la que en aquella oportunidad se pronunciara la Corte fue con ocasión del proceso de revisión constitucional del Decreto 333 de febrero 24 de 1992, "por el cual 
se declara el Estado de Emergencia Social". En esta oportunidad se da inicio a esta nueva etapa constitucional con la declaratoria de constitucionalidad del referido decreto. Las precisiones que sobre la separación de poderes se hicieran en esta decisión son como se puede observar, generales, aludiendo al carácter incipiente y nuevo de la jurisprudencia de este Tribunal. Sobre la institución se resalta la necesidad de superar la visión rígida que sobre esta se tenía para dar paso a una más flexible que permitiera desarrollar los fines de la Carta de 1991.

En la Sentencia C-449 de 1992, como consecuencia de la demanda interpuesta por el ciudadano Jorge Arango Mejía, con posterioridad elegido Magistrado de esta Corporación, en contra del Artículo 33 (parcial) de la Ley 9 de 1991 por la cual se dictan normas generales a las que deberá sujetarse el Gobierno Nacional para regular los cambios internacionales, la Corte declara la inconstitucionalidad de la norma acusada al considerar que la facultad que se atribuye al Congreso para "revisar" contratos viola la Constitución porque el Congreso pretende "revisar", cuando sólo está facultado para autorizar o aprobar los contratos celebrados por el ejecutivo, lo que a la postre sería una invasión indebida en funciones asignadas a este último.

Sobre la teoría de la separación de poderes señala Mejía (1992):

La teoría de la separación de poderes ha sido reelaborada por la doctrina constitucional, pasando de su concepción clásica inicial de Montesquieu, en la que cada rama del poder hacía una sola y misma cosa -legislar, ejecutar, juzgar-, a una nueva concepción en la que los diversos órganos del poder se articulan mediante funciones separadas, destinadas a la consecución de unos mismos y altos fines del Estado (artículos $2^{\circ}, 3^{\circ}, 113,365$ y 366 de la Constitución política de Colombia, 1991). Es por eso por lo que el Congreso y el Gobierno deben coordinarse, pero no duplicarse en las actividades que requieren su concurso simultáneo (p.21).
Aquí empieza a notarse la labor asumida por la primera Corte, como se ha dado por denominar al grupo de magistrados que integraron esta Corporación desde su creación -1992- hasta inicios de los años 2000. Labor que consistió en dar una fundamentación conceptual a la naciente jurisprudencia constitucional, sentando las bases doctrinarias que permitieron el desarrollo posterior de su postura. En otro aparte se refiere a dicha institución en los siguientes términos:

Conforme a la Corte Constitucional (1992), surge pues una interdependencia de las distintas ramas y órganos del poder, lo cual implica incluso un control recíproco entre ellos. No se trata por tanto de una fragmentación del poder del Estado sino de una articulación a través de la integración de varias fuerzas. Un nexo sistemático vincula entonces los fines esenciales del Estado y su organización. Como ya lo tiene establecido la reciente jurisprudencia de la Corte Constitucional en su primera sentencia en Sala Plena", "la visión de una rígida separación de los poderes debe ser superada en la concepción que concilia el ejercicio de funciones separadas -que no pertenecen a un órgano sino al Estado- con la colaboración armónica para la realización de sus fines, que no son otros que los del servicio a la comunidad"(C-007,1992). "Todo ello sin perjuicio de la constatación según la cual las ramas y órganos del Estado, al lado de sus funciones primigenias, desempeñan algunas funciones típicas de otras ramas y órganos. Se rompe así la matriz órgano-función, como ya lo había establecido la jurisprudencia de la Corte Suprema de Justicia desde 1985. (p.57)

Sentencia C-179 de 1994, en la revisión constitucional del proyecto de ley estatutaria No. 91/92 Senado y 166/92 Cámara "Por la cual se regulan los estados de excepción en Colombia", cuyo Magistrado Ponente fue el célebre Carlos Gaviria Díaz, se hace un análisis riguroso de varias de las instituciones que empezarían a abrirse camino en la jurisprudencia constitucional de esta Corporación, manteniendo el carácter novísimo y vanguardista que se le ha reconocido a la Primera Corte, que con recursos pedagógicos explicaba la importancia de la separación de poderes en los siguiente términos: 
La constitución rígida, la separación de las ramas del poder, la órbita restrictiva de los funcionarios, las acciones públicas de constitucionalidad y de legalidad, la vigilancia y el control sobre los actos que los agentes del poder llevan a término, tienen, de modo inmediato, una única finalidad: el imperio del derecho y, consecuentemente, la negación de la arbitrariedad. Pero aún cabe preguntar: ¿́por qué preferir el derecho a la arbitrariedad? La pregunta parece necia, pero su respuesta es esclarecedora de los contenidos axiológicos que esta forma de organización política pretende materializar: porque sólo de ese modo pueden ser libres las personas que la norma jurídica tiene por destinatarias: particulares y funcionarios públicos. Desdibujar la frontera que separaba a los unos de los otros, fue la obsesión del constitucionalismo revolucionario del siglo XVIII y continúa siendo el leit-motiv del moderno Estado de derecho.

Debe reconocerse el esfuerzo estructurador que se le imprimía a las decisiones iniciales de la Corte Constitucional, atendiendo al renovado impulso que en el ámbito jurídico y político le imprimió al país la expedición de la Constitución Política de 1991 y la creación de un Tribunal Constitucional que debía construirse desde sus cimientos, para sentar la base de su propio devenir como institución en el andamiaje anquilosado de la sociedad jurídica colombiana. Esta tarea estructuradora, en ocasiones pedagógica, sirvió como fundamento de las instituciones que la Carta del 91 creaba pero que requerirían de desarrollo posterior mediante la jurisprudencia de su guardiana, la Honorable Corte Constitucional.

Sentencia C-198 de 1994, en ejercicio de la acción pública de inconstitucionalidad se demandó la inexequibilidad del numeral $3^{\circ}$. del artículo 6o. (parcial) de la Ley 5a. de 1992, que a la postre regulara los juicios de control político que debiera adelantar el Congreso de la República. La demanda acusaba a la norma de manejar un lenguaje que permitía la realización de juicios de control político a terceros que por su naturaleza no podían ser objeto de este, desconociendo que por nuestro diseño institucional dicha figura solo debía predicarse respecto al ejecutivo y no a funcionarios distintos.

Por otra parte, atendiendo a los límites del control que asignó la Constitución política de Colombia (1991) en cabeza del Congreso, refiere:

La misma Constitución establece el principio de separación entre las ramas del poder público y prohíbe al Congreso y a cada una de sus Cámaras inmiscuirse en asuntos de competencia privativa de otras autoridades; pero, sobre todo, es perentoria al determinar que las decisiones de la Administración de Justicia son independientes. La expresión contenida en el numeral 3o. del artículo 6o. acusado debe interpretarse como una manifestación del control político dentro de un sistema de gobierno presidencial (Art.6, p.4).

De esta manera empieza a perfilarse el alcance que a la expresión "separación de poderes" debe dársele en contextos ya delimitados, como en el que el Congreso tiene funciones propias que han sido previamente asignadas por la Constitución, lo que a su turno sirve de limitante en relación con la rama del poder ejecutivo.

Sentencia C-167 de 1995, a través de esta sentencia la Corte se pronunció sobre la exequibilidad del artículo 88 del Decreto 410 de 1971 (Código de Comercio), mediante el cual se le asignaba a la Contraloría General de la República la labor fiscalizadora sobre los bienes fiscales administrados por las Cámaras de Comercio. En esta oportunidad el Tribunal Constitucional declaró la constitucionalidad de la norma acusada, señalando la necesidad de especialización funcional que subyace al principio de separación de poderes, criterio impuesto por la misma Constitución de 1991. Al respecto refirió:

La Constitución Política de Colombia (1991) desarrollo el principio de la separación de poderes, dispuso que son ramas del poder público, la legislativa, la ejecutiva y la judicial; con lo cual se entiende la determinación superior del constituyente, de 
especializar la toma de las decisiones y las acciones del poder público, con el propósito no sólo de buscar mayor eficiencia en el logro de los fines que le son propios, sino también, para que esas competencias así determinadas, en sus límites, se constituyeran en controles automáticos de las distintas ramas entre sí, y, para, según la afirmación clásica, defender la libertad del individuo y de la persona humana.

Por otra parte, como reconocimiento de la gran tarea estatal y, en consecuencia, de las múltiples funciones creadas por el constituyente del 91, se empieza a reconocer el papel que dentro de la separación y división de poderes juegan los denominados órganos independientes e independientes.

En este sentido:

Agrega la Constitución política de Colombia (1991), en su lógica distributiva de las funciones públicas que, además de los órganos que integran a aquellas Ramas del poder público, existen otros, autónomos e independientes, para el cumplimiento de las demás funciones del Estado (art. 113 C.N.), denominados "órganos de control", entre los que se encuentran, además del Ministerio Público, la Contraloría General de la República (artículo 117), a cuyo cargo está la vigilancia de la gestión fiscal y el control de resultados de la administración. Esta lógica de separación, independencia y autonomía otorgada a la Contraloría General de la Nación anuncia por sí misma, la concepción que se consagra en la nueva Constitución del control fiscal” (p.20-21).

Sentencia C-615 de 1996, en esta decisión la Corte se pronuncia sobre la demanda de constitucionalidad contra el parágrafo del artículo 11 y los parágrafos 1 y 3 del artículo 21 de la Ley 191 de 1995 "por medio de la cual se dictan disposiciones sobre Zonas de Fronteras", porque al sentir del actor el legislador, mediante la norma acusada, facultó al Gobierno Nacional para regular materias atribuidas constitucionalmente al Banco de la República, excediendo con ello las fun- ciones atribuidas a éste en detrimento de un órgano autónomo cuya capacidad de ejercicio se vería seriamente mermada con tal disposición.

Cabe advertir que en esta oportunidad la Corte Constitucional no se pronunció específicamente sobre la figura de la separación de poderes, pero sí sobre el principio del "ejercicio armónico" de los poderes, que con posterioridad le sirviera de fundamento para desarrollar el principio de separación y división de poderes. En tal sentido dijo:

Cada órgano del Estado tiene, en el marco de la Constitución, un conjunto determinado de funciones. El desarrollo de una competencia singular no puede realizarse de una manera tal que su resultado signifique una alteración o modificación de las funciones que la Constitución ha atribuido a los demás órganos. Se impone un criterio o principio de "ejercicio armónico" de los poderes, de suerte que cada órgano se mantenga dentro de su esfera propia y no se desfigure el diseño constitucional de las funciones.

Sentencia C-312 de 1997, esta decisión de la Corte Constitucional empieza por plantear problemas concretos en cuanto a la separación y división efectiva de las ramas del poder público, de tal manera que a través de mecanismos legales se pudiera impedir la independencia de ramas entre sí, al otorgarse en favor de unas mejores condiciones respecto a las otras. En esta oportunidad la Corporación decide el estudio de constitucionalidad promovido por una demanda ciudadana en contra del literal b) - parcial - del artículo $1^{\circ}$ de la Ley $4^{\mathrm{a}}$ de 1992.

La referida norma acusada es una ley marco que define los parámetros en materia salarial y pensional de las ramas del poder público incluyendo las entidades autónomas como la fiscalía general y el Ministerio público, que debía ser reglamentada por parte del Gobierno Nacional.

En el estudio realizado por la Corte Constitucional, a través del Magistrado Ponente, Dr. Eduardo Ci-

Pensamiento Americano Vol. 14 - No. 27 - p.p. 57-79 • 2021 • Enero-Junio • Corporación Universitaria Americana • Barranquilla, Colombia • ISSN-e: 2745-1402 http://publicaciones.americana.edu.co/index.php/pensamientoamericano/index 
fuentes Muñoz, se refiere específicamente al tema de separación e independencia de los poderes públicos, cuya transcripción se hace in extenso para mejor entendimiento y en el que se señala, entre varias otras cuestiones, i). La manera en que surge el principio de separación de poderes, ii). La discusión acerca de la pertinencia de la consagración constitucional de la división tripartita del poder presentada en la Asamblea Nacional Constituyente y iii). El resultado de la dicha discusión mediante la expedición del artículo 113 de la Constitución de 1991. En este sentido:

De acuerdo con la constitución política de Colombia (1991) El principio de la separación de los poderes surge como resultado de la búsqueda de mecanismos institucionales enderezada a evitar la arbitrariedad de los gobernantes y a asegurar la libertad de los asociados. Por esta razón, se decide separar la función pública entre diferentes ramas, de manera que no descanse únicamente en las manos de una sola y que los diversos órganos de cada una de ellas se controlen recíprocamente (p.19).

Desde las primeras formulaciones de este principio en la edad moderna, en el siglo XVII, se han planteado diversos modelos de configuración de la separación de los poderes, pero por encima de las modalidades planteadas prevalece la concepción de que la separación de las ramas del poder público es inherente al régimen democrático y constituye uno de sus elementos procedimentales de legitimación. (...)”

Se decide seguir con el modelo tripartito de división de los poderes, pero admitiendo la existencia de otros órganos autónomos e independientes. Al respecto preceptúa el artículo 113 de la Carta:

Constitución política de Colombia (1991) Artículo 113. Son ramas del Poder Público, la legislativa, la ejecutiva y la judicial. "Además de los órganos que las integran existen otros, autónomos e independientes, para el cumplimiento de las demás funciones del Estado. "Los diferentes órganos del Estado tienen funciones separadas, pero colaboran armónicamente para la realización de sus fines.
En consecuencia, en el Capítulo I del Título V de la Constitución, acerca de la estructura del Estado, se hace referencia ya no únicamente a los órganos de las ramas Ejecutiva, Legislativa y Judicial, sino también al Ministerio Público, a la Contraloría General de la Nación y a la Organización Electoral. Además, debe agregarse que en la Constitución también se le reconoce autonomía al Banco de la República y a la Comisión Nacional de Televisión”.

En el citado artículo 113 de la Constitución política de Colombia (1991) se expresa que las ramas y los órganos del Poder Público son autónomos e independientes, aun cuando deben colaborar para la realización de sus fines. Para garantizar la autonomía de las distintas ramas (SIC) y órganos, la Constitución establece una serie de disposiciones. Esas normas hacen relación, entre otras cosas, a las funciones de cada órgano y a sus condiciones de autonomía administrativa y presupuestal; a los procedimientos para el nombramiento, sanción o destitución de los titulares de esas instituciones; al período de ejercicio de estos y a las inhabilidades, incompatibilidades y prohibiciones a que están sujetos; a las condiciones que deben cumplir los ciudadanos para acceder a determinados cargos, y constituyen una especie de muro de protección de la autonomía de los diversos órganos y ramas del Poder, muro cuyos componentes se asemejan o diferencian de mecanismos creados con el mismo objetivo en otros países y sobre cuya adecuación para el fin deseado se pueden realizar diferentes juicios.

Sentencia C-189 de 1998, La ciudadana Elsa Beatriz Tobón Duarte presenta demanda de inconstitucionalidad contra los artículos 80 (parcial) y 81 (parcial) de la Ley 42 de 1993, cuyo objeto es "Sobre organización del sistema de control fiscal financiero y los organismos que lo ejercen”. Fundamenta sus cargos en el sentido de señalar que esta Ley limita la independencia del poder fiscalizador de las Contralorías. De otro parte, la Corte sale al paso a este argumento señalando que no es función de esta llenar las contradicciones y vacíos legales que al interior de la legislación existan, toda vez que es en el Congreso donde deben debatirse dichas incongruencias como 
desarrollo de su función legislativa. Es una posición autorrestrictiva que dentro de la Corte ha estado en constante debate contra un ala más activista a su interior. Finalmente, en la construcción de su argumentación y como respuesta al cargo promovido en contra de la norma censurada, este Tribunal refiriéndose al principio de separación de poderes dijo:

La Carta magna de Colombia (1991) mantiene el principio de separación de poderes (CP art. 113) pero le confiere una naturaleza más compleja, en un doble sentido. De un lado, admite que existen órganos autónomos cuyas funciones no pueden ni deben ser encajadas dentro de la división clásica en tres ramas del poder, como los órganos de control y la organización electoral. Y, de otro lado, la Carta no sólo admite, sino que promueve la existencia de controles recíprocos entre las distintas ramas y órganos autónomos, por medio del clásico mecanismo de pesos y contrapesos, como bien lo resalta uno de los intervinientes (p.21).

En Sentencia de la Corte Constitucional C-100 (1996) expreso la corporación, que la consagración de ramas del poder y de órganos autónomos se lleva a cabo "con el propósito no sólo de buscar mayor eficiencia en el logro de los fines que le son propios, sino también, para que esas competencias así determinadas, en sus límites, se constituyeran en controles automáticos de las distintas ramas entre sí, y, para, según la afirmación clásica, defender la libertad del individuo y de la persona humana" (p.36).

En tal contexto, la actora y los intervinientes tienen igualmente razón en insistir en que, conforme a esa nueva visión del principio de separación de poderes, la Carta otorga no sólo autonomía orgánica sino también unas funciones propias y específicas a las contralorías (CP arts. 113, 119, 267 y 268), por lo cual es claro que estos órganos de control no hacen parte de la Rama Ejecutiva ni desarrollan, como actividad, principales tareas administrativas, como las que adelantan la administración central y las administraciones seccionales. Por ello, tal y como esta Corporación ya lo había señalado, la Constitución quiso "distinguir nítidamente la función propiamente administrativa del Ejecutivo de la función fiscalizadora de la Contraloría, pues consideró que la confusión de tales funciones comportaba efectos perjudiciales para la marcha del Estado" (C100, 1996). Esto se desprende con nitidez no sólo del texto constitucional, que explicita que la tarea propia de estas entidades es la vigilancia y el control fiscal de la administración (CP arts.119 y 267) sino, además, del examen de los debates constituyentes, en donde claramente se señaló que "no se debe confundir la función fiscalizadora con la función administrativo o gubernativa, pues son de naturaleza totalmente distinta y se ejerce por actos también diferentes" (Herrera, 2002).

\subsection{Período del 2001 al 2020}

El nuevo milenio trajo nuevos dilemas constitucionales como consecuencia de las diversas modificaciones que a la estructura constitucional intentaran los gobiernos de los presidentes Álvaro Uribe Vélez -tanto en su primer como segundo mandato-, y con posterioridad los dos periodos institucionales del presidente Juan Manuel Santos. Las modificaciones que promovieron desde sus gobiernos a la Constitución de 1991, a través de diversos Actos Legislativos, pusieron a la Corte Constitucional en la necesidad de perfeccionar su jurisprudencia alrededor de principios y ejes estructurales de la Carta del 91 con el fin de señalar los límites de reforma que a la postre debían ser considerados por parte tanto del Gobierno Nacional, como por el Congreso de la República. El nuevo siglo impone la necesidad de crear claridad conceptual respecto a las figuras referenciadas, todo con el fin de salvaguardar la integridad de la Constitución en una cultura política que amenaza constantemente con contrariar sus ejes estructurales.

A continuación, basta señalar que por efectos prácticos se procura excluir las sentencias meramente confirmadoras de principio o de reiteración, en aras de concretar el análisis alrededor de las decisiones más importantes de la jurisprudencia constitucional y sobre las cuales gravita la mayor parte del desarrollo del principio de separación de poderes, división y equilibrio de poderes. 
Sentencia C-970 de 2004, en una de las primeras demandas de constitucionalidad en contra de un Acto Legislativo bajo el cargo de sustituir la Constitución (recientemente creada dicha institución en la jurisprudencia constitucional en la Sentencia C-551 de 2003), se oponen dos ciudadanos al artículo $4^{\circ}$ transitorio del Acto Legislativo 02 de 2003 al considerar que las facultades otorgadas en éste al Presidente de la República no solo modifican la estructura constitucional sino que además la sustituyen al vulnerar principios estructurales de la Constitución de 1991.

Refiriéndose al principio de separación de poderes en la Constitución de 1991, la Corte expresa en esta decisión el carácter flexible que el Constituyente primario le otorga a la figura jurídica para resaltar de esta manera la necesidad de acoplar dicha institución a los cambios necesarios en la vida institucional de la sociedad colombiana, al respecto señala:

A diferencia del modelo absoluto y rígido de separación de poderes, la Constitución de 1991, adopta un sistema flexible de distribución de las distintas funciones del poder público, que se conjuga con un principio de colaboración armónica de los diferentes órganos del Estado y distintos mecanismos de freno y contrapeso entre los poderes.

De esta suerte, la Constitución de 1991 se encuentra a tono con los sistemas políticos democráticos constitucionales, que como señala Loewenstein, se caracterizan porque la Constitución reúne como elementos mínimos fundamentales, entre otros, los siguientes: De una parte, se formula una diferenciación de las diversas tareas del Estado y su asignación a diversos órganos estatales, y, de otra parte, se adopta un mecanismo de cooperación de los diversos detentadores del poder (Loewenstein, 1965, p. 110).

La Constitución colombiana dedica su Título V a la Organización del Estado, y en el Capítulo 1, sobre estructura del Estado, después de señalar, en el artículo 113, que son ramas del poder público la legislativa, la ejecutiva y la judicial, y que, además de los órganos que las integran existe otros, autónomos e independien- tes, para el cumplimiento de las demás funciones del Estado, precisa que "los diferentes órganos del Estado tienen funciones separadas pero colaboran armónicamente para la realización de sus fines”.

En líneas posteriores señala cómo el constituyente de 1991 atenúa el principio de separación de poderes, además de mostrar que la estructura constitucional está diseñada bajo la idea de propiciar la colaboración armónica entre los órganos públicos garantizando en igual medida un sistema de controles recíprocos (lo que se desarrollará posteriormente como el sistema de pesos y contrapesos o check and balances):

El modelo por el cual optó el constituyente de 1991, Art.116 mantiene el criterio conforme al cual, por virtud del principio de separación, las funciones necesarias para la realización de los fines del Estado se atribuyen a órganos autónomos e independientes. Sin embargo, la idea de la separación está matizada por los requerimientos constitucionales de colaboración armónica y controles recíprocos. Por virtud del primero, se impone, por un lado, una labor de coordinación entre los órganos a cuyo cargo está el ejercicio de las distintas funciones, y, por otro, se atenúa el principio de separación, de tal manera que unos órganos participan en el ámbito funcional de otros, bien sea como un complemento, que, según el caso, puede ser necesario o contingente, o como una excepción a la regla general de distribución funcional, como cuando la Constitución señala que el Congreso ejercerá determinadas funciones judiciales o que la ley podrá atribuir excepcionalmente función jurisdiccional en materias precisas a determinadas autoridades administrativas (p.21).

Los controles recíprocos, por su parte, se encuentran consagrados en diversas disposiciones constitucionales, como aquellas que establecen y desarrollan la función de control político del Congreso sobre el gobierno y la administración, o las que regulan los órganos autónomos de control y vigilancia. En conjunto, la estructura constitucional descrita responde al modelo de frenos y contrapesos que tiene el propósi-

Pensamiento Americano Vol. 14 - No. 27 - p.p. 57-79 • 2021 • Enero-Junio · Corporación Universitaria Americana • Barranquilla, Colombia • ISSN-e: 2745-1402 http://publicaciones.americana.edu.co/index.php/pensamientoamericano/index 
to, no solo de obtener mayor eficiencia en el desarrollo de las funciones a través de las cuales el Estado atiende a la satisfacción de sus fines, sino, y principalmente, de garantizar una esfera de libertad para las personas, por efecto de la limitación del poder que resulta de esa distribución y articulación de competencias. Sentencia C-757 de 2008, en esta oportunidad la Corte Constitucional estudia la demanda presentada en contra del Acto Legislativo 01 de 2007, que modifica la institución de la moción de censura y que al decir del actor trasgrede el principio de separación de poderes y de equilibrio de poderes, sustituyendo de esta manera un pilar importante de la Constitución de 1991.

En esta sentencia C-1040 (2005), cuyo Magistrado Ponente fue Rodrigo Escobar Gil, se hace especial énfasis en mostrar que el principio de separación de poderes y de equilibrio de poderes son ejes definitorios de la Carta del 91, ejes estructurales de ésta y por lo tanto no susceptibles de sustitución a través del poder de reforma del Constituyente derivado. Al respecto se lee:

De acuerdo a la Sentencia C-1040 (2005) Específicamente sobre el principio de separación de poderes en el escenario de la sustitución de constitución, la Corte ha expresado que dicho principio puede tenerse como definitorio de la identidad de la Constitución de 1991, pero que es claro que el mismo admite diversidad de formulaciones, todas compatibles con el postulado básico definitorio de la identidad de la Constitución, de manera que no toda modificación de la manera como en un momento se configuró el principio en la Constitución puede tenerse como una sustitución de la misma”(p.65).

En el presente caso se ha argumentado que, en el escenario de la moción de censura, el Acto Legislativo 01 de 2007 altera de tal manera el principio bicameral contenido en la Constitución de 1991, que es factor esencial, a su vez, del principio de separación de los poderes, que en realidad se está ante una sustitución parcial de la Constitución. Para ello se manifiesta que al atribuir a cada una de las cámaras por separado la competencia para aprobar la moción de censura se ge- nera un desequilibrio entre el legislativo y el ejecutivo que compromete la independencia de este último.

Sobre el particular observa la Corte que cuando se introducen reformas a los instrumentos de control interorgánico previstos en la Constitución, es posible que un órgano se vea fortalecido, en contraste con otro o con otros que, como efecto de la reforma, se ven debilitados en sus competencias, o sometidos a controles más estrictos o recortados en su capacidad de vigilar o condicionar la actuación de otros. Pero mientras tales reformas se mantengan dentro del ámbito del principio de separación de poderes como eje definitorio de la identidad de la Carta Fundamental, no puede decirse que las mismas hayan dado lugar a una sustitución de la Constitución. Existe sustitución cuando se suprime el principio mismo y se reemplaza por otro distinto y de carácter opuesto. Así, por ejemplo, ocurriría cuando una reforma condujese a la concentración de las funciones del Estado en un sólo órgano, que escaparía, por consiguiente, a cualquier esquema de frenos y contrapesos. Lo mismo cabría decir de una reforma por cuya virtud se afirmase la plena autonomía y supremacía de un órgano que lo hiciese inmune a cualquier tipo de control por otros.

En esas eventualidades se sentaría un principio incompatible con la Constitución de 1991 y el esquema de separación de poderes que se desprende de sus distintas disposiciones. Pero no ocurre lo mismo cuando dentro del esquema de la separación de los poderes y sin desnaturalizarlo, se hace una nueva distribución de competencias o se modifica la manera como operan determinados controles recíprocos entre los órganos del Estado, o se alteran las condiciones de procedencia de estos. Se trata de consideraciones de oportunidad y de conveniencia sobre el diseño institucional, que caben dentro del ámbito competencial del poder de reforma y que, por consiguiente, no pueden considerarse como una sustitución de la Constitución.

Sentencia de la Corte Constitucional C - 141 (2010), cuyo Magistrado Ponente fue el Dr. Humberto Sierra Porto, se realizó el control automático de la Ley 1354 de 2009 que convocaba a un referendo

Pensamiento Americano Vol. 14 - No. 27 - p.p. 57-79 • 2021 • Enero-Junio • Corporación Universitaria Americana • Barranquilla, Colombia • ISSN-e: 2745-1402 http://publicaciones.americana.edu.co/index.php/pensamientoamericano/index 
constitucional y se sometía a consideración del pueblo una reforma constitucional del Artículo 197 para permitir que quien haya ostentado la Presidencia de la República por dos periodos consecutivos pudiera aspirar a un tercero. Cabe destacar la importancia política y jurídica que dicha decisión representaba para el país bajo el entendido que el presidente de turno no contaba con un real sistema de contrapesos por parte del Congreso de la República al tener aplastante mayoría de sus copartidarios. Es decir, el sistema de pesos y contrapesos, de equilibrio de poderes, de división de poderes y de separación de poderes dependía exclusivamente de lo que la Corte Constitucional decidiera (p.45).

Con una primera reelección del ejecutivo ya se había trastocado el diseño constitucional originario y se veía seriamente mermado el sistema de contrapesos o check and balances del legislativo hacia el ejecutivo. A la jurisprudencia del Tribunal Constitucional le era otorgada la responsabilidad de decidir si dicho referendo y propuesta de modificación constitucional estaba o no ajustado a los ejes definitorios de la Carta del 91. A través del juicio de sustitución dio por dar respuesta a este interrogante, encontrando que se sustituía la Constitución de 1991 con esta medida al trastocar seriamente el principio de separación de poderes, tan celosamente diseñado en el seno de la Asamblea Nacional Constituyente.

Cabe destacar que frente al principio de separación de poderes la Corte empieza por mencionar que existen dos modelos cuya estructura difiere, además de cómo dichos modelos materializan el adecuado equilibrio de poderes a través de un sistema de frenos y contrapesos que permiten un equilibrio democrático, y en este sentido se señaló:

La Corte Constitucional en sentencia C-141 de 2010, ha permitido que la jurisprudencia constitucional ha reconocido que existen "dos modelos de separación de poderes.” El primero de estos modelos defiende una delimitación funcional rigurosa, como medio para acotar el poder, a partir del entendimiento de que una distribución preci- sa y equilibrada de las labores estatales, en la cual cada órgano cumple una tarea preestablecida, es una condición suficiente para mantener a dichos órganos del poder dentro de sus límites constitucionales. A su vez, la separación funcional rígida es concebida como una estrategia que permite asegurar las libertades de los ciudadanos (p.42).

De conformidad con lo indicado, en la Constitución de 1991 ese sistema no es de confusión, sino de separación de poderes y las relaciones que se presentan entre los diversos órganos, en lugar de configurarse a partir de la dependencia jerárquica, se estructuran con base en la paridad, así como en las responsabilidades encomendadas a cada uno y en los controles recíprocos que se cumplen en el entramado institucional.

De acuerdo con la Corte Constitucional en sentencia C-141 de 2010, Según los datos del derecho comparado, con fundamento en la pluralidad de órganos y en su separación, la organización del poder ejecutivo y la manera como, de acuerdo con esa organización, se desarrollen sus relaciones con los demás poderes y, en especial con el legislativo, se determina el específico tipo de sistema de gobierno contemplado en una Constitución. De la amplia tipología que, como modalidades más importantes, comprende al presidencial y al parlamentario, el Constituyente colombiano de 1991 optó por un sistema presidencial, conforme se desprende del artículo 115 de la Carta vigente (p.42).

En líneas siguientes se evidencia que el sistema presidencial instaurado por la Constitución de 1991 buscaba la colaboración armónica y no la imposición de un sistema rígido del principio de separación de poderes, en palabras de la Corte:

De acuerdo con la Corte Constitucional en sentencia C-141 de 2010, del esquema brevemente descrito se desprende que la separación de poderes prohijada en la Carta no obedece a una concepción rígida e inflexible, sino que admite la colaboración armónica de los distintos órganos, pertenecientes 
a diversas ramas, para la realización de los fines estatales, tal como lo demuestran las relaciones que, de acuerdo con la Constitución, el presidente mantiene con las ramas legislativa y judicial. La colaboración en el cumplimiento de los cometidos del Estado es, sin embargo, una de las formas de relación entre los poderes, ya que vínculos distintos también surgen entre ellos cuando se trata de ejercer el control recíproco, encomendado a cada una de las ramas respecto del desarrollo de las funciones confiadas a las otras (p.42-43).

Sentencia C-288 de 2012, en esta providencia se reitera en gran parte lo que hasta este momento ha desarrollado la jurisprudencia constitucional, sobre todo lo dicho en la Sentencia C-141 de 2010, aunque debe mencionarse que se vuelve a la calificación del principio de separación de poderes como eje definitorio de la Constitución y a la postre señalar su caracterización en los siguientes términos:

De acuerdo con la Sentencia C-288 (2012) se puede concluir que, el principio de separación de poderes es un rasgo definitorio del Estado Constitucional. Este eje estructural, para el caso particular de la Carta Política, se caracteriza por (i) la delimitación precisa, mediante reglas jurídicas, de las competencias de cada uno de los poderes, junto con la definición de su estructura institucional; (ii) la aplicación de dicho principio para el cumplimiento de la doble función de racionalización de la actividad del Estado y protección de los derechos y libertades de los ciudadanos ante la arbitrariedad propia de todo poder omnímodo; y (iii) la incorporación de mecanismos para el funcionamiento del sistema de frenos y contrapesos, agrupados en los criterios de colaboración armónica y de controles recíprocos o interorgánicos (p.68).

Por otra parte, se muestra cómo la autonomía y la independencia judicial son expresiones de este principio, al decir:

De acuerdo con la Sentencia C-288 (2012) La autonomía e independencia del poder judicial son expresiones del principio de separación de poderes. Los jueces, en cuanto ejercen la función jurisdiccional, están supeditados exclusivamente a la aplicación del ordenamiento jurídico vigente y al análisis imparcial de los hechos materia de debate judicial. El ejercicio de la competencia jurisdiccional, así comprendida, acepta la inclusión de mecanismos de colaboración armónica y de controles recíprocos, condición de que no incidan o interfieran en el ámbito de la adopción de decisiones judiciales (p.69).

Sentencia C-285 de 2016, en ejercicio de la acción pública de constitucionalidad, el ciudadano Carlos Santiago Pérez Pinto presentó demanda de inconstitucionalidad contra los artículos 15 (parcial), 16, 17, 18, 19 y 26 (parcial) del Acto Legislativo 02 de 2015, cuyo estudio correspondió al Magistrado Ponente Luis Guillermo Guerrero Pérez, quien a su turno hizo un recuento detallado del avance en la jurisprudencia de esta alto tribunal alrededor del principio de separación de poderes y su alcance en el juicio de sustitución. Se reitera el carácter de eje axial al principio de separación de poderes, ampliamente desarrollada hasta ahora por la jurisprudencia constitucional, y se añaden criterios a la caracterización con el objeto de clarificar su identificación en los cada vez más limitados juicios de sustitución. A respecto se dice:

La Corte Constitucional en Sentencia C-285 de 2016, establece que el principio de separación de poderes constituye un elemento esencial del ordenamiento superior en tanto instrumento de limitación de poder y garantía de los derechos y libertades y de la realización de los fines estatales. Y tal como fue concebido por el constituyente, exige: (i) la identificación de las funciones del Estado; (ii) la atribución de dichas funciones a órganos estatales diferenciados, en principio, de manera exclusiva y excluyente; (iii) la garantía de que cada órgano goce de independencia, en el sentido de que debe estar exento de injerencias externas en el desarrollo de su función; (iv) la garantía de que cada órgano goce de autonomía, 
en el sentido de que debe poder desenvolverse y desplegar su actividad por sí mismo, y autogobernarse (p.33).

Sentencia C-332 de 2017, como consecuencia del proceso de revisión de los instrumentos jurídicos que se han desplegado para la implementación de los Acuerdos de Paz suscritos entre el Gobierno Nacional y el grupo insurgente FARC-EP, se presentó acción de inconstitucionalidad en contra del Acto Legislativo 01 de 2016, "por medio del cual se establecen instrumentos jurídicos para facilitar y asegurar la implementación y el desarrollo normativo del Acuerdo Final para la Terminación del Conflicto y la Construcción de una Paz Estable y Duradera” En esta ocasión se realizó nuevamente un juicio de sustitución al tenor del cargo formulado por los actores que señalaban que dicha reforma constitucional vulneraba el principio de separación de poderes, de equilibrio de poderes y el sistema de pesos y contrapesos o check and balances. Después de realizado el estudio se resolvió declarar la inexequibilidad de los literales h) y j) del artículo $1^{\circ}$ del Acto Legislativo 01 de 2016, bajo la consideración de encontrar transgredido el principio de separación de poderes, ya definido como eje axial no susceptible de modificación sin atentar contra la naturaleza misma de la Constitución del 91.

Respecto a esta institución jurídica se reiteró jurisprudencia y se agregó:

La Corte Constitucional (2017) reafirma que el principio de separación y equilibrio de poderes es un eje estructural de la Constitución, cuya sustitución escapa al ámbito del poder de reforma de que es titular el Congreso. Esta situación opera, entre otros supuestos, cuando la enmienda constitucional confiere competencias ampliadas a una de las ramas del poder público, en detrimento de las facultades de los demás poderes, llegándose a un vaciamiento de estas. Asimismo, la jurisprudencia demuestra que la preservación del principio mencionado, a través del control de las reformas constitucionales por vicios en la competencia del Congreso, debe tener en cuenta la tendencia hacia la hipertrofia del poder presidencial, razón por la cual existe un vínculo estrecho y verificable entre la integridad del principio de separación de poderes y la contención de las competencias del ejecutivo (p.22).

\section{Contexto legal}

Referirse al contexto legal del principio del equilibrio de poderes públicos en Colombia, implica necesaria y obligatoriamente hacer mención del acto legislativo 02 de 2015 Congreso de la República, "Por medio del cual se adopta una reforma al equilibrio de poderes y reajuste institucional y se dictan otras disposiciones"

Como primera medida, el acto legislativo adiciona los incisos cuarto y quinto, en el sentido de reglamentar que, quienes ocupen el segundo lugar en las elecciones presidenciales y así lo corrobore la autoridad electoral, tendrá derecho a ocupar una curul en el Senado de la República, así mismo el candidato vicepresidencias que acompañe la formula, podrá ocupar una curul en la cámara de representantes, y así mismo se replicará en las elecciones regionales, es decir, Gobernaciones y Alcaldías, quienes ocupen podrán ser diputados y concejales respectivamente, siempre y cuando acepten ocupar la curul correspondiente.

Como segunda medida, otras modificaciones destacables a la constitución que introdujo el acto legislativo es, por ejemplo, los asuntos relacionados con los remplazos de los miembros de corporaciones públicas y de igual forma sobre el quorum de las entidades cuando se presentes situaciones que den lugar a remplazo de sus miembros, de igual manera el acto legislativo se refiere a el número de curules que tiene cada departamento del país en la Cámara de Representantes, de acuerdo con el número de habitantes que se registre que residen en cada territorio; también sobre el régimen disciplinario de los funcionarios públicos y en especial de la rama judicial, por ser esta la que a su vez y en ejercicio de sus funciones constitucionales y legales elige o incide con la escogencia de los organismos de control que son y ejercen total independencia 
de las tres ramas del poder público.

Una de las instituciones ha durante los años ha sufrido más críticas, desde periodísticas hasta judiciales, debido a su función y los resultados de la misma durante su existencia, ha sido la comisión de acusaciones de la cámara de representantes, la cual constitucionalmente se encarga de adelantar investigaciones de los funcionarios que gozan de fuero constitucional y que en virtud de ello, la justicia y los órganos de control pierden conocimiento para su debida investigación, el Acto legislativo 02 de 2015 se refirió a dicha comisión y sus funciones, así como también a la expresa prohibición que se mantiene todavía vigente, referente a la reelección presidencial en Colombia.

\section{Alcance y efectos del principio de equili- brio de poderes en Colombia}

\subsection{División de poderes púbicos}

Puede decirse que la división de poderes es un principio que tiene vigencia en algunas formas de gobierno en los cuales, se reconoce principalmente, el poder legislativo, judicial y ejecutivo, y estos mismos son ejercidos por organismos del gobierno diferentes e independientes el uno del otro, en algunos estados, la relación que existe entre cada uno de estos poderes públicos es que el poder legislativo ejerciendo las facultades conferidas por el constituyente primario, sirve para contribuir objetivamente en la escogencia de los miembros del poder judicial e incluso en algunos estados también de miembros del poder ejecutivo, no es el caso de Colombia.

\subsection{Separación de poderes}

Referirse a separación de poderes implica enunciar que es necesario que previamente se encuentren dividas en ramas o poder público, las funciones estatales que ejercen algunas formas de estado, tal y como se ha dicho con anterioridad, legislar, administrar justicia y gobernar. La separación de poderes implica dos elementos fundamentales, el primer de ellos, requiere indispensablemente que exista una disposi- ción superior, es decir, una constitución que goce de legitimidad y reconocimiento internacional que acredite y respalde que en dicho estado se ejercerán por separado y con funciones y limites específicamente demarcados, las funciones propias de un estado y que además de tener claramente definidas sus funciones y propósitos, se ejercerá dicha función por organismos estatales diferentes para cada una de las ramas o poderes públicos.

La diferencia fundamental entre el concepto anteriormente mencionado y la separación de poderes públicos, es que el primero implica únicamente el reconocimiento de individualizar, desligar y entender particularmente en tres los poder de un estado y la separación de poderes requiere de que cada uno de los poderes del Estado los ejerzan organizamos de manera autónoma e independientey además que debe tener un soporte en la constitución o documento jerárquicamente superior que regule la forma de gobierno, e instituciones de la nación; y en esa disposición legal tener funciones taxativas, facultades y limites definidos.

\subsection{Equilibrio de poderes}

Dicho lo anterior con respecto al equilibrio de poderes y la separación de éstos, se aborda el principio integrador de las anteriores definiciones, y se trata del equilibrio de poderes públicos que tan necesario resulta para cualquier Estado en los intentos y esfuerzos realizados para mantener vigente y con legitimidad la forma de gobierno que se encuentre establecida. El equilibrio de poderes de conformidad con la Enciclopedia Jurídica Omeba, se da en el derecho público moderno. Es un nombre que corresponde a una determinada forma de organización del gobierno del Estado, susceptible de excluir, o al menos, de dificultar grandemente, toda manifestación de hegemonía o preponderancia de un órgano de autoridad sobre los demás, cuyo conjunto constituye ese gobierno. Y tal estructura, es el término de un largo y secular proceso de perfeccionamiento, lento pero progresivo, del gobierno político de los pueblos.

También puede entenderse como, la sinergia y ar-

Pensamiento Americano Vol. 14 - No. 27 - p.p. 57-79 • 2021 • Enero-Junio • Corporación Universitaria Americana • Barranquilla, Colombia • ISSN-e: 2745-1402 http://publicaciones.americana.edu.co/index.php/pensamientoamericano/index 
monía que debe existir en la práctica y el ejercicio de las funciones de los poderes públicos de un estado, es decir, que en ninguna circunstancia una de las ramas del poder interfiera en las competencias de otra, o que en los casos en los que tengan que intervenir 2, o incluso, las 3 ramas del poder se conserven y respeten los limites previamente establecidos por la constitución o leyes regulatorias para tales eventos. Así mismo en dichos que necesiten pluri-participación de los poderes públicos, es indispensable contar con formular que permitan establecer cuál de las ramas del poder, prima ante las demás, cuando de asumir competencias en situaciones se trata.

\subsection{Efectos Jurídicos}

Los efectos jurídicos del principio de equilibrio de poderes públicos en Colombia tienen dos acepciones En primer lugar y haciendo referencia al estado Colombiano, la Constitución Política colombiana, contempla y presenta un diseño en el cual en primera medida reconoce la división de los poderes públicos, así mismo otorga funciones y competencias específicas a cada una de las ramas, aclarando que estas, tendrán autonomía e independencia y tendrán vigencia en todo el territorio Colombiano, sin excepciones y los lugares en el mundo donde el estado colombiano ejerza soberanía, de igual forma otorga competencias a otras disposiciones de carácter general para que regulen los limites en el funcionamiento ordinario de las ramas de poder público colombiano, por ejemplo el máximo órgano constitucional, que podríamos decir que representa la rama judicial para nuestro ejemplo, a pesar de que es conocido como el órgano de cierre en materia constitucional, y que las tres ramas del poder de cierta forma someten sus decisiones y proposiciones a que este órgano los declare constitucional, tiene también los límites que le impone el articulo 241 superior.

Con respecto al poder legislativo, el artículo 150 superior, crea el congreso de la república de Colombia y establece de igual forma cuales son funciones y procedimientos que deberán cumplirse cíclicamente y así mismo otorga facultades al congreso para la ex- pedición de una ley que les permita regularse internamente con respecto a los procedimientos para el cumplimiento de la función misional."

Las funciones antes mencionadas, tanto la del congreso como de la corte constitucional han generado en los últimos años algunas tensiones, por no mencionar también el choque de trenes que se presenta al interior de la rama judicial, entre la citada Corte Constitucional, el Consejo de Estado e incluso con la Corte suprema de justicia, esas controversias competen principalmente al diseño y de la rama judicial propiamente dicha, retomaremos entonces con un ejemplo reciente de enfrentamiento de competencias al aplicar funciones entre el congreso de la república, la Corte Constitucional y el gobierno nacional.

El reciente caso que generó dudas y opiniones divididas frente a quien le correspondía la competencia de definir de fondo la situación, fue el caso de la aprobación en la plenaria del Senado de la Republica de las 16 curules que le serian otorgadas a las víctimas del conflicto armado en Colombia en virtud del Acuerdos de Paz que el gobierno firmó con las FARC. La diversidad de criterios para el particular consistió en el número de votos afirmativos para la proposición de aprobar o no dichas curules. El Senado de la República para entonces estaba conformado constitucionalmente por 102 miembros, pero 3 de sus miembros se encontraban privados de la libertad con una suspensión en el ejercicio de sus curules, lo que indica que para el momento de la votación, el Senado no contaba con un numero de 102 miembros como naturalmente es, sino que, por el contrario, se encontraba conformado por 99 de sus miembros, quienes daban lugar a la totalidad del cuerpo colegiado, en consecuencia la mayoría absoluta de ese número es 50 , exactamente el mismo número de votos que tuvo la opción de aprobar la proposición. Es aquí donde comienzan las opiniones divididas y teorías frente al particular.

Casos como el anteriormente descrito, enfrentan a las tres ramas del poder público frente a un tema común, por cuanto el proyecto hace parte de una iniciativa del gobierno, que a su vez debía ser aprobada 
por el Congreso de la República y finalmente tener aprobación constitucional y legal por la Corte Constitucional y el Consejo de Estado, respectivamente.

Por otra parte, y queriendo también dar alcance a los efectos jurídicos que tiene el principio de equilibrio de poderes públicos se cita al autor Berning (2009) en su artículo "La división de poderes en las transformaciones del Estado de derecho (II)":

Según Berning (2009) La división o distribución de los poderes equilibradamente (balance-idee) no significa una separación entre ellos y la consiguiente debilitación del Estado, sino que se busca un equilibrio entre los intereses de los grupos sociales sobre la base de un compromiso político. Esto exige una acción concertada de las diferentes fuerzas políticas para que el Estado pueda funcionar, pero en ningún caso la división implica que aquél venda parte de su capacidad de mandar o prohibir a cambio de garantizar la libertad personal. Montesquieu, cuando alude a los poderes legislativo y ejecutivo, distingue con perfecta nitidez, sin confundirlos, entre distribution des pouvoirs y separation, empleando la primera expresión cuando se refiere a la esfera política y reservando la segunda al plano jurídico. Otra cuestión es que, teniendo en cuenta la famosa frase de Montesquieu de que no existe libertad «lorsque dans le même personne ou dans le même corps de magistrature, la puissance legislative est réunie a la puisance exécutrice», se parte de una separación personal y organizativa de ambos poderes, lo cual plantea problemas en la coordinación de su funcionamiento. Hay que crear, entonces, una organización estatal que funcione eficazmente $y$, al mismo tiempo, garantice un equilibrio y control (check and balance) entre los diversos poderes. Se adscribe la función legislativa a nobleza y pueblo en dos Cámaras diferentes, existiendo el derecho de veto entre ambas, derecho que se amplía al rey, lo cual es, en definitiva, una forma de participación de éste en la legislación. Por otra parte, el poder legislativo tiene también sus medios de control sobre el ejecutivo, en primer lugar, por los propios límites internos de éste: «car l'exécution ayant ses limites par sa nature, il est inutile de la borner», $\mathrm{y}$, además, porque el legislativo controla el cumplimiento de las leyes y tiene el derecho de perseguir penalmente a los ministros" (p.135).

Con relación al poder ejecutivo, plantea dificultades, su delimitación y fines. Este poder no se limita a realizar una actividad de ejecución, sino también una actividad normativa, que en algunos casos (decretos legislativos y decretos-leyes) tiene rango de ley.

\section{Conclusiones.}

El equilibrio del poder como política significa la utilización de este término para referirse a ciertas políticas estatales o bien, al principio capaz de inspirar dichas políticas. Se ha descartado anteriormente "el equilibrio de poder como distribución”, la situación de desequilibrio. De ahí, por tanto, que ya no se aborde aquí la política que bajo el significado de equilibrio responde a finalidades de supremacía.

Se trata, por tanto, de la política de aquellos estados que deliberadamente tratan de impedir la preponderación de un estado en particular y de mantener un equilibrio aproximado de poder entre los principales rivales (Hoffmann, 1977:131.). De ahí que se pueden citar los principios contenidos en la obra de Lord Bolingbroke y David Hume, de carácter prudente y moderador, como ideas-guías de lo que se podría denominar política de equilibrio. En la contemporánea teoría de relaciones internacionales el discurso normativo de Hans Morgenthau (1978) es el mejor ejemplo del equilibrio del poder como política.

En el terreno histórico, los principios de la política de equilibrio hallan su mejor expresión, en el mecanismo de "holder of the balance" jugado por la política exterior británica durante los siglos XVIII y XIX.

Si el equilibrio de poder como política de equilibrio es el resultado de una acción extrema del estado, esta política se ve condicionada por las características de la estructura exterior en los estados en los estados 
que están obligados a actuar. De ahí, por tanto, que el equilibrio del poder como política sea indisociable del tercer y último significado enunciado.

Esto es, el equilibrio del poder como sistema. La política del equilibrio del poder desde el carácter condicionante que sobre la elaboración de esta tiene el sistema internacional. Las reglas de dichas políticas dependerán de la estructura del sistema, distinguiendo entre sistema bipolar y sistema pluripolar.

\section{Referencias}

Acto legislativo 01 de 2016. (2016, 7 de julio). Congreso la República. Diario Oficial No. 49.927

Acto legislativo 01 del 2007. (2007, 27 de junio). Congreso de la República.

Berning, A. (2009, 1 de enero). La división de poderes en las transformaciones del Estado de Derecho. Noticias jurídicas edición digital. https://noticias.juridicas.com/conocimiento/articulos-doctrinales/4422-la-division-de-poderes-en-las-transformaciones-del-estado-de-derecho-y-ii/

Cerra,E.(2017).Delaautonomía delavoluntad:noción,limitaciones y vigencia. Advocatus, 2(29). https://doi.org/10.1804l/01240102/advoca-tus.29.1661

Constitución Política De Colombia. (1991). 2da Ed. Legis

Decreto 333 de 1992. (1992, 24 de febrero). Congreso de la República. Diario Oficial No. 40.350

Decreto 410 de 1971. (1971, 16 de junio) Congreso de la República. Diario Oficial No.33.339

Díaz, E. (2012). Desarrollo histórico del Principio de Separación de Poderes. Revista de Derecho, (38),240-270.

Herrera,A. (2002). Análisis práctico sobre los criterios de distinción de las funciones públicas, 17 Revista de Derecho 17. 143-161.

Hoffmann, S. (1977). Equilibrio del poder. Enciclopedia Internacional de las Ciencias Sociales.

Ley 1354 de 2009. (2009, 8 de septiembre). Congreso de la República. Diario Oficial No. 47.466

Ley 191 de 1995. (1995, 23 de junio). Congreso de la República. Diario Oficial No. 41.903

Ley 4 de 1992. (1992, 18 de mayo). Congreso de la República. Diario Oficial No. 40.451 
Ley 42 de 1993. (1993, 26 de enero). Congreso de la República. Diario Oficial No. 40.732

Ley 9 de 1991. (1991, 17 de enero). Congreso de la República. Diario Oficial No. N. 39.634

Loewenstein, K. (1965). Political Power and Governmental Process. University of Chicago.

Lozano, J. (2004). El Triángulo del E-learning. http://www.noticias.com/articulo/25-09-2004/jose-lozano/trianguloelearning-47l6.html

Mirkine-Guetzévitch, B. (2008). Derecho Constitucional Internacional. Editorial Reus, S. A.

Morgenthau, H. (1978). La lucha por el poder.

Morín, E. (2003). Introducción al pensamiento complejo. Gedisa.

Sentencia 1040/05. (2005, 19 de octubre). Corte Constitucional (Manuel José Cepeda Espinosa, Rodrigo Escobar Gil, Marco Gerardo Monroy Cabra, Humberto Antonio Sierra Porto, Álvaro Tafur Galvis \& Clara Inés Vargas Hernández M.P) https://www.corteconstitucional.gov.co/relatoria/2005/C-1040-05.htm

Sentencia 55l/03. (2003, 9 de Julio) Corte Constitucional (Eduardo Montealegre Lynett M.P) https://www.corteconstitucional. gov.co/relatoria/2003/C-551-03.htm

Sentencia C-004/1992. (1992, 24 de febrero) Corte Constitucional. (Eduardo Cifuentes Muñoz M.P) https://www.corteconstitucional.gov.co/relatoria/1992/C-004-92.htm

Sentencia C-100/96. (1996, 7 de marzo). Corte Constitucional. (Alejandro Martínez Ceballos M.P) https://www.corteconstitucional.gov.co/relatoria/1996/C-100-96.htm

Sentencia C-141/10. (2010, 26 de febrero) Corte Constitucional. Humberto Sierra Porto M.P.https://www.corteconstitucional. gov.co/relatoria/2010/c-141-10.htm.

Sentencia C-167/95. (1995, 20 de abril). Corte Constitucional. (Fabio Morón Díaz M.P) https://www.corteconstitucional.gov. co/relatoria/1995/c-167-95.htm

Sentencia C-179/94. (1994, 13 de abril). Corte Constitucional. (Carlos Gaviria Diaz M.P) https://www.corteconstitucional.gov. co/relatoria/1994/C-179-94.htm

Sentencia C-189/98. (1998, 06 de mayo). Corte Constitucional (Alejandro Martínez Caballero M.P). https://www.funcionpublica. gov.co/eva/gestornormativo/norma.php?i=5734

Sentencia C-198/94. (1994, 21 de abril) Corte Constitucional (Vladimiro Naranjo Mesa M.P) https://www.corteconstitucional. gov.co/relatoria/1994/C-198-94.htm

Sentencia C-285/16. (2016, 1 de junio). Corte Constitucional (Luis Guillermo Guerrero Pérez M.P) https://www.corteconstitucional.gov.co/relatoria/2016/c-285-16.htm

Sentencia C-288/12. (2012, 18 de abril). Corte Constitucional (Luis Ernesto Vargas Silva M.P) https://www.corteconstitucional. gov.co/RELATORIA/2012/C-288-12.htm

Sentencia C-312 de 1997. (1997, 25 de noviembre). Corte Constitucional. (Eduardo Cifuentes Muñoz M.P). https://www. corteconstitucional.gov.co/relatoria/1997/C-312- https:// www.funcionpublica.gov.co/eva/gestornormativo/norma. php?i=6919

Sentencia C-332/17. (2017, 17 de mayo). Corte Constitucional (Antonio José Lizarazo Ocampo M.P) https://www.corteconstitucional.gov.co/relatoria/2017/C-332-17.htm

Sentencia C-449/92. (1992, 09 de julio). Corte Constitucional (Alejandro Martínez Caballero M.P) https://www.corteconstitucional.gov.co/relatoria/1992/c-449-92.htm

Sentencia C-615/96. (1996, 13 de noviembre) Corte Constitucional (Eduardo Cifuentes Muñoz M.P) https://www.corteconstitucional.gov.co/relatoria/1996/c-615-96.htm

Sentencia C-630/14. (2014, 03 de septiembre) Corte Constitucional. Gloria Stella Ortiz Delgado M.P. http://www.avancejuridico. com/actualidad/ultimoscomunicados/C-630-14(D-10080). html 
Sentencia C-757/08. (2008, 30 de julio). Corte Constitucional. (Rodrigo Escobar Gil M.P) https://www.corteconstitucional.gov. co/relatoria/2008/C-757-08.htm

Sentencia C-970/04. (2004, 7 de octubre) Corte Constitucional. Rodrigo Escobar Gil M.P. https://www.corteconstitucional.gov. co/relatoria/2004/c-970-04.htm

Vergara Estévez, J. (2012). Democracia y participación en Jean-Jacques Rousseau. Revista de filosofía, 68, 29-52. https://dx.doi. org/10.4067/S0718-43602012000100004 
